\title{
Investigation of the Inhibiting Effect of Cerium Ions on the Corrosion Behavior of OC404 Stainless Steel in Sulfuric Acid Medium
}

\author{
Desislava Guergova ${ }^{1}$, Emilia Stoyanova $^{1}$, Dimitar Stoychev ${ }^{*}$, Ivalina Avramova $^{2}$ and Plamen Stefanov ${ }^{2}$ \\ ${ }^{1}$ Institute of Physical Chemistry, Bulgarian Academy of Sciences, “Acad. G. Bonchev” Str., block 11, Sofia 1113, \\ Bulgaria \\ ${ }^{2}$ Institute of General and Inorganic Chemistry, Bulgarian Academy of Sciences, “Acad. G. Bonchev" Str., block 11, \\ Sofia 1113, Bulgaria
}

\begin{abstract}
The inhibiting effect of $\mathrm{Ce}^{4+}$ ions, introduced in the form of $\mathrm{Ce}\left(\mathrm{SO}_{4}\right)_{2}$, on the corrosion electrochemical behavior of stainless steel OC404, has been studied in sulfuric acid corrosion medium $\left(0.05 \mathrm{M} \mathrm{H}_{2} \mathrm{SO}_{4}\right)$.

On the basis of the obtained data on the values of the density of the corrosion current ( $\mathrm{i}_{\text {corr }}$ ), evaluated using the dependences E-lgi, both in inhibited and uninhibited corrosion medium, the degree of corrosion protection in the presence of the inhibitor was calculated, as well as the fraction of surface coverage (Q) the electrode surface with inhibitor. These studies were carried out with samples of non-treated thermally steel (SS) and thermally treated steel $\left(\mathrm{SS}_{\mathrm{t.t}}\right)$. The cathodic reaction of reduction of the oxidative component of the medium $\mathrm{Ce}^{4+}$ was found to be the basic driving force of the conjugated anodic process, leading to a transition of $\mathrm{SS}_{\mathrm{t.t.}}$ from active into passive state. Thereupon an option is created to form an efficient protective film of phase type on the $\mathrm{SS}_{\mathrm{t} \text {.t. }}$ surface reaching a degree of inhibition efficiency of about $98 \%$.

In order to elucidate the nature of the inhibiting action of cerium ions the influence of the value of the equilibrium oxidation-reduction potential of the $\mathrm{Ce}^{4+} / \mathrm{Ce}^{3+}$ ion pair was investigated as well as that of the exchange current of the oxidation-reduction process upon the processes of passivation of the studied steel.
\end{abstract}

The obtained results give the reason to classify the cerium ions as cathode type of inhibitor having oxidative action.

Keywords: Corrosion, sulfuric acid medium, stainless steel, $\mathrm{Ce}^{4+} / \mathrm{Ce}^{3+}$ ion pair.

\section{INTRODUCTION}

The use of OC404 type of stainless steels (SS) for the production of catalytic converters for exhaust gas purification, containing $\mathrm{NO}_{\mathrm{x}}, \mathrm{SO}_{\mathrm{x}}, \mathrm{CO}$, hydrocarbons etc., which are evolved in the processes of burning in internal combustion engines (ICE) as well as in other combustion systems, is based on their suitable physical-mechanical and physical-chemical properties [1,2]. The modifying of their surfaces with oxides of rare earth metals and other elements (Ce, $\mathrm{La}, \mathrm{Y}, \mathrm{Zr}, \mathrm{Al}$ etc.) is connected with the specific functions of these oxides as "supports" of additionally deposited on them actual catalytically active systems $(\mathrm{Pt}, \mathrm{Rh}$, $\mathrm{Pd}$, different kinds of spinels etc.) as well as with their stabilizing effect in regard to preserving the specific working surface area of the catalytic converters in case of exploitation at high temperature $[3,4]$.

In our previous investigation it was shown that, electrochemically deposited layers of $\mathrm{CeO}_{2}$ and $\mathrm{Al}_{2} \mathrm{O}_{3}$ on SS lead to a substantial improvement of the stability to corrosion of the steel in oxidative $\left(0.1 \mathrm{~N} \mathrm{HNO}_{3}\right)[5,6]$ and non-oxidative $\left(0.1 \mathrm{~N} \mathrm{H}_{2} \mathrm{SO}_{4}\right)$ [7-9] aggressive media. This

*Address correspondence to this author at the Institute of Physical Chemistry, Bulgarian Academy of Sciences, "Acad. G. Bonchev" Str., block 11, Sofia 1113, Bulgaria; Tel: (+354-2) 720608; Fax: (+359-2)9712688;

E-mail: stoychev@ipchp.ipc.bas.bg established positive effect was explained by their stabilizing influence on the passive state of the steel, as a result of the action of cerium oxides, and in particular as efficient cathodic coating [5,9], as well as by the ascertained occurrence of a cathodic depolarization process of reduction of $\mathrm{CeO}_{2}$ to $\mathrm{Ce}_{2} \mathrm{O}_{3}$, instead of the depolarizing reaction of hydrogen evolution in $0.1 \mathrm{~N} \mathrm{H}_{2} \mathrm{SO}_{4}$ [9].

As the $\mathrm{Ce}_{2} \mathrm{O}_{3}$ being formed is chemically unstable and it is being dissolved in acidic media [10], the amount of $\mathrm{CeO}_{2}$, which has been transformed into $\mathrm{Ce}_{2} \mathrm{O}_{3}$ on the surface of SS, with the increasing time interval of in aggressive medium, is decreasing at the expense of enriching the medium with $\mathrm{Ce}^{3+}$ ions.

A strong impression in the course of these investigations was made by the fact, that even upon reaching a degree of complete dissolution of the $\mathrm{CeO}_{2}$ layer (absence of Ce upon XPS scanning of the SS surface), the stationary corrosion potential $\left(E_{s t}\right)$ of SS remained more positive than $E_{s t}$ of steel not coated with $\mathrm{CeO}_{2}$. This effect, as well as the available literature data on the inhibitory influence of $\mathrm{Ce}^{4+}$ and $\mathrm{Ce}^{3+}$ ions in the course of corrosion of various kinds of steel and aluminum in neutral media, including media containing chlorine ions [10-19] gave us the reason to suppose that in addition to the protective effect of the $\mathrm{CeO}_{2}$ layers deposited electrochemically by us we should probably add also the inhibitory action of cerium ions, transferred into the corrosion medium. Obviously most of the rare earth ionic 
inhibitors were used in neutral or approximately neutral media. The corrosion inhibition of rare earth ions in strong acidic medium was less studied. Recently the synergistic effect of $\mathrm{Ce}^{4+} /$ organic compounds mixtures for cold-rolled steel corrosion inhibition in $1.0 \mathrm{M} \mathrm{H}_{2} \mathrm{SO}_{4}$ media were also investigated [20-25].

In view of these considerations the aim of the present study was to observe the influence of cerium ions as corrosion inhibitor of OC404 stainless steel in non-oxidizing medium of $0.05 \mathrm{M} \mathrm{H}_{2} \mathrm{SO}_{4}$.

\section{EXPERIMENTAL DETAILS}

\subsection{Specimens}

The test specimens used in this study were prepared using a sheet of OC404 type stainless steel with a thickness of $50 \mu \mathrm{m}$. The composition of the steel in wt. \% was: $20.0 \%$ $\mathrm{Cr}, 5.0 \% \mathrm{Al}, 0.02 \% \mathrm{C}$, the rest being $\mathrm{Fe}$. The specimens were investigated before (SS) and after thermal treatment $\left(\mathrm{SS}_{\mathrm{t.t}}\right)$ at $450^{\circ} \mathrm{C}$ for $2 \mathrm{~h}$ in air.

\subsection{Solutions}

The model aggressive solution $\left(0.05 \mathrm{M} \mathrm{H}_{2} \mathrm{SO}_{4}\right)$ was prepared by dilution of analytical grade $98 \% \mathrm{H}_{2} \mathrm{SO}_{4}$ ("Merck") with distilled water. In order to evaluate the inhibitory effect of $\mathrm{Ce}^{4+}$ salt, variable concentrations of $\mathrm{Ce}\left(\mathrm{SO}_{4}\right)_{2} \cdot 4 \mathrm{H}_{2} \mathrm{O}$ from 0.1 to $1500 \mathrm{ppm}$ were added to $0.05 \mathrm{M}$ $\mathrm{H}_{2} \mathrm{SO}_{4}$.

\subsection{Electrochemical (Corrosion) Characterizations}

The stationary corrosion potential $\left(\mathrm{E}_{\mathrm{st}}\right)$ of the samples under investigation was determined by direct measurement of the dependence " $\mathrm{E}_{\mathrm{st}}$-time" at open circuit vs mercurous

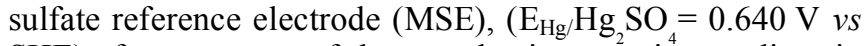
$\mathrm{SHE}$ ) after exposure of the samples in corrosion medium in the absence and in the presence of $\mathrm{Ce}^{4+}$ ions. In the latter case the effect of the temperature of the corrosion medium was also studied within the temperature interval $25 \div 100{ }^{\circ} \mathrm{C}$.

After being kept in the corrosion medium for a definite time, the specimens were taken out, rinsed carefully with distilled water several times. The treated specimens were dried in air at room temperature before the XPS and SEM investigations.

The electrochemical (anodic and cathodic) behavior of the samples $(10 \times 10 \times 0.05 \mathrm{~mm})$ was studied in a standard three-electrode thermostatted cell $(100 \mathrm{ml}$ volume). The working electrode had the form of a square of dimensions 10 $\mathrm{mm} \times 10 \mathrm{~mm}$ and working area of $1 \mathrm{~cm}^{2}$. The non-working surface of the electrode was isolated using a suitable lacquer, resistant to acids. A counter electrode, representing a platinum plate $(10 \times 10 \times 0.6 \mathrm{~mm})$, and the same MSE reference electrode were used. All potentials in the text are related to MSE electrode. The anodic and cathodic polarization curves were obtained using a 273 EG\&G potentiostat/galvanostat (Germany) and computer-aided processing of the results according to an "Echem" program, with a potential sweeping rate of $10 \mathrm{mV} / \mathrm{s}$ within a range of potentials varying from -1.100 to $+1.100 \mathrm{~V}$. The potentiodynamic curves were obtained starting from the stationary corrosion potential $\left(\mathrm{E}_{\mathrm{st}}\right)$ in anodic and in cathodic direction. The time interval for reaching the stationary corrosion potential $\left(\mathrm{E}_{\mathrm{st}}\right)$ is up to 100 minutes. For plotting each anodic or cathodic curve we used a separate electrode (identical with the previous one). All the potentiodynamic electrochemical experiments were carried out at least in triplicate.

\subsection{Chemical Characterizations}

The chemical composition and the oxidation state of the elements on the surface being formed (before and after heattreated) were studied using X-ray photoelectron spectroscopy (XPS). The XPS studies were performed in a VG Escalab II system with $\mathrm{Al} \mathrm{K}_{\alpha}$ radiation $(h v=1486.6 \mathrm{eV})$ and total instrumental resolution of $\sim 1 \mathrm{eV}$. The vacuum in the chamber was $10^{-8} \mathrm{~Pa}$. The binding energy (BE) was referred to the $\mathrm{C} 1 \mathrm{~s}$ line (of adventitious carbon) at $285.0 \mathrm{eV}$. The elemental concentrations were evaluated based on the integrated peak areas after Shirley-type of linear background subtraction using theoretical Scofield's photo-ionization cross-sections.

\subsection{Structure Characterizations}

Microstructure and morphology of the SS surface before and after the treatment were examined by scanning electron microscopy, using a JEOL JSM 6390 electron microscope (Japan), equipped with an ultrahigh resolution scanning system in a regime of secondary electron image (SEI). The accelerating voltage was $20 \mathrm{kV}$.

\section{RESULTS AND DISCUSSION}

\subsection{Chronopotentiometric Studies of $\mathrm{SS}$ and $\mathrm{SS}_{\mathrm{t} \text {.t. }}$ in $\mathbf{0 . 0 5}$ $\mathrm{M} \mathrm{H}_{2} \mathrm{SO}_{4}$}

The measurement of the stationary corrosion potential ( $\mathrm{E}_{\mathrm{st}}$ ) for $\mathrm{SS}$ and $\mathrm{SS}_{\mathrm{t} \text { t. }}$ in $0.05 \mathrm{M} \mathrm{H}_{2} \mathrm{SO}_{4}$ at open circuit shows that for the non-treated thermally steel $\mathrm{E}_{\mathrm{st}}=\sim-0.300 \mathrm{~V}$, while for the thermally treated sample $\mathrm{E}_{\mathrm{st}}=\sim-0.980 \mathrm{~V}$.

The shifting of $E_{s t}$ in positive direction (Fig. 1) and establishing values with about $300 \mathrm{mV}$ more positive than its value at the moment of immersing the SS sample into $0.05 \mathrm{M} \mathrm{H}_{2} \mathrm{SO}_{4}$ solution $\left(\mathrm{E}_{\mathrm{in}}=-0.600 \mathrm{~V}\right)$ is due to reorganizing the composition and the structure of the native passive film on SS. A series of studies on similar types of stainless steels proved that such a change of $\mathrm{E}_{\mathrm{st}}$ is due to the tendency of self-passivation of such steels, determining definite changes in the natural passive film [26]. As it is seen from Table 1, upon immersion into sulfuric acid medium it is enriched in chromium and the ratio $\mathrm{Cr} / \mathrm{Fe}$ is strongly changed in favor of the chromium. At the same time the Al content is substantially decreased.

The analysis of the XPS spectra of the same samples (the total concentrations of the elements, listed in Table 1) shows (see also detailed data in Table 2 and Fig. 2 - the spectra, respectively), that iron is contained in the native film in the form of $\mathrm{Fe}^{0}(39.3 \%)$ as well as $\mathrm{Fe}^{3+}(60.7 \%)$; the chromium is in the form of metal $(39.7 \%)$ as well as ions $\mathrm{Cr}^{3+}(39 \%)$ and $\mathrm{Cr}^{6+}(21.3 \%)$, and the aluminum is in the form of $\mathrm{Al}^{3+}$ ions $(100 \%)$. After exposure of the samples to $0.05 \mathrm{M} \mathrm{H}_{2} \mathrm{SO}_{4}$ solutions $(50 \mathrm{~h})$, the ratio between elemental iron and the oxides of iron grows up considerably in favor of the elemental iron. The ratio of $\mathrm{Cr}^{3+}$ to metallic chromium is increasing about four times, while the $\mathrm{Cr}^{6+}$ ions vanish. 


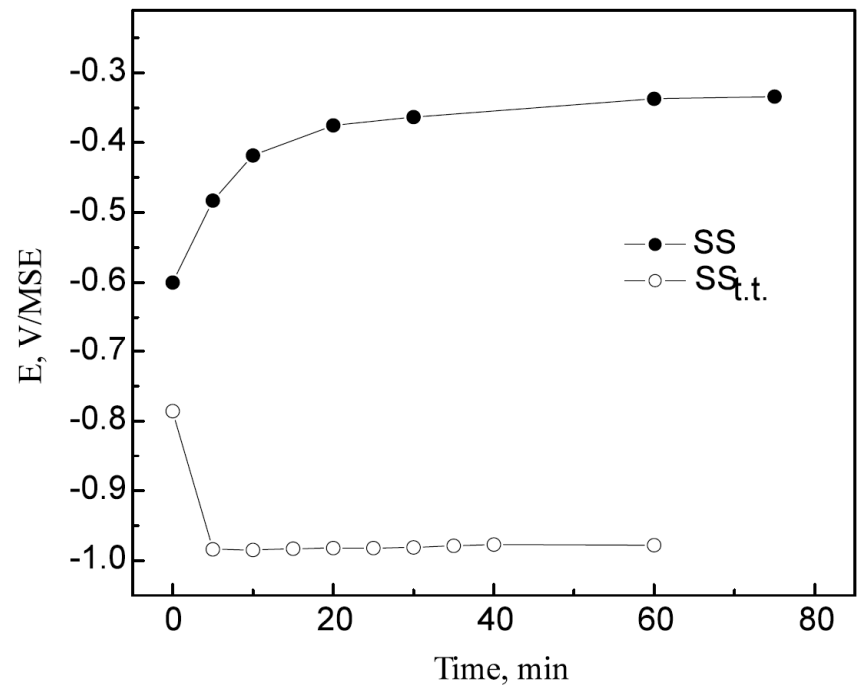

Fig. (1). Open circuit potential vs time curves of $\mathrm{SS}$ and $\mathrm{SS}_{\text {t.t. }}$ in $0.05 \mathrm{M} \mathrm{H}_{2} \mathrm{SO}_{4}$.

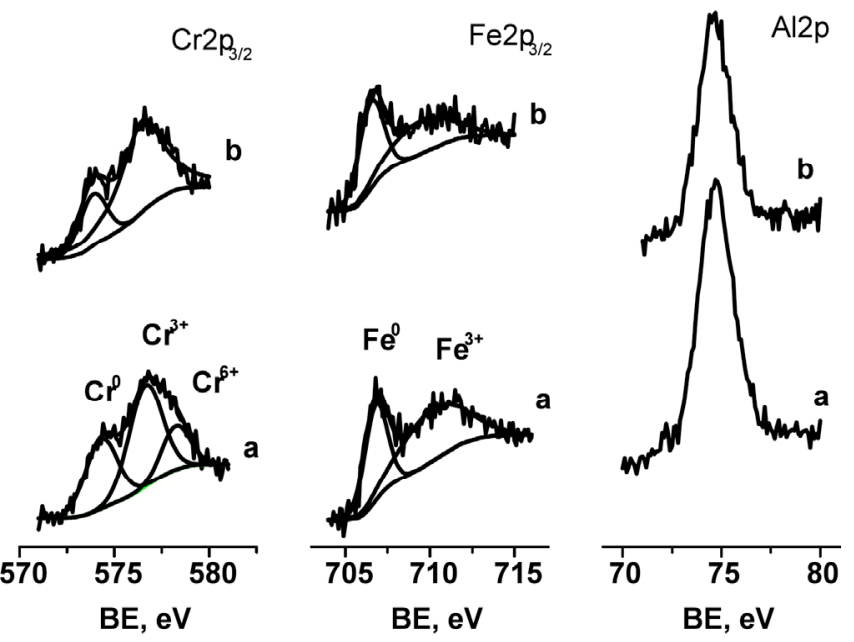

Fig. (2). $\mathrm{Cr} 2 \mathrm{p}_{3 / 2}, \mathrm{Fe} 2 \mathrm{p}_{3 / 2}$ and $\mathrm{A} 12 \mathrm{p} \mathrm{X}$-ray photoelectron spectra of $\mathrm{SS}$ (a) and $\mathrm{SS}_{\text {t.t. }}$ after $50 \mathrm{~h}$ immersion in $0.05 \mathrm{M} \mathrm{H}_{2} \mathrm{SO}_{4}$ (b) (The chemical states of the elements are indicated).
For $\mathrm{SS}_{\text {t.t. }}$ the corrosion potential at the moment of immersion into $0.05 \mathrm{M} \mathrm{H}_{2} \mathrm{SO}_{4}$ solution $\left(\mathrm{E}_{\text {in }}=-0.780 \mathrm{~V}\right)$, is more negative with $\sim 180 \mathrm{mV}$ compared to the potential for the non-treated thermally steel (Fig. 1). The establishment of unchanging with the course of time potential $E_{\text {st }}(\sim-0.980 \mathrm{~V})$ in this case becomes much more rapid (after $\sim 5 \mathrm{~min}$ ). The registered significantly more negative values of $\mathrm{E}_{\mathrm{st}}$ for $\mathrm{SS}_{\mathrm{t} \text { t.t. }}$, in our opinion, are owing to the strong cracking of the native passive on the SS surface (Fig. 3). Most probably the reason for this loss of the passivity feature of the stainless steel surface is some revealed sections on the surface, determining several times higher concentration of iron-containing agglomerates (active anodic sections) in the surface layer (Table 1). Obviously their amount starts to be dominating in the value of $\mathrm{E}_{\mathrm{st}}$ for $\mathrm{SS}_{\mathrm{t} \text {.t. }}\left(\mathrm{E}_{\mathrm{st}}\right.$ for pure iron, measured by us in $0.05 \mathrm{M} \mathrm{H}_{2} \mathrm{SO}_{4}$, is $\sim-0.912 \mathrm{~V}$ ).

Both the composition (Table 1) and the state of the elements in the surface layer of $\mathrm{SS}_{\mathrm{t} . t}$ are strongly different (see detailed date in Table 3 and Fig. 4 - the spectra, respectively) compared to those for SS. After the thermal treatment of the steel samples all the three components, included in the composition of the steel (Fe, Cr, Al) in its surface layer, are present only in their oxide state. After $50 \mathrm{~h}$ of exposure to sulfuric acid medium the surface layer is modified and the iron is registered both in the form of $\mathrm{Fe}^{0}$ and $\mathrm{Fe}^{3+}$ (at a ratio $48.2 \%$ to $51.8 \%$ ); the registered chromium is in the form of $\mathrm{Cr}^{0}$ and $\mathrm{Cr}^{3+}$ (at a ratio $18.7 \%$ to $81.3 \%$ ), while the detected aluminum is in the form of $\mathrm{Al}^{0}$ and $\mathrm{Al}^{3+}$ (at a ratio $28.3 \%$ to $71.7 \%$ ). These results are in accordance with the microscope observations of the samples of thermally treated steel prior to and after their exposure to $0.05 \mathrm{M} \mathrm{H}_{2} \mathrm{SO}_{4}$, showing the development of total corrosion and the appearance of pitting corrosion as a consequence of disruption of the passive state of the thermally treated steel (Fig. 5).

\subsection{Chronopotentiometric Studies of $\mathrm{SS}$ and $\mathrm{SS}_{\mathrm{t} \text { t.t. }}$ in $\mathbf{0 . 0 5}$ $\mathrm{M} \mathrm{H}_{2} \mathrm{SO}_{4}$, Containing $\mathrm{Ce}^{4+}$ Ions}

Fig. (6) illustrates the analogous E- $\tau$ dependencies at open circuit, obtained upon immersion of $\mathrm{SS}$ and $\mathrm{SS}_{\mathrm{t} . \mathrm{t} .}$ in

Table 1. Distribution of the Elements (in at. \%) on the Surface of SS and $\mathrm{SS}_{\text {t.t. }}$ Samples Before and After $50 \mathrm{~h}$ Time Interval of Immersion in $0.05 \mathrm{M} \mathrm{H}_{2} \mathrm{SO}_{4}$

\begin{tabular}{|c|c|c|c|c|c|c|c|c|c|}
\hline Samples & $\begin{array}{l}\text { O, } \\
\text { at. \% }\end{array}$ & $\begin{array}{c}\mathrm{Fe}, \\
\text { at. \% }\end{array}$ & $\begin{array}{l}\mathrm{Cr}, \\
\text { at. \% }\end{array}$ & $\begin{array}{l}\text { Al, } \\
\text { at. } \%\end{array}$ & $\begin{array}{c}\text { Ce, } \\
\text { at. \% }\end{array}$ & $\underset{\%}{\mathbf{C r} / \mathbf{F e},}$ & $\underset{\%}{\mathbf{A l} / \mathbf{F e},}$ & $\underset{\%}{\mathbf{A l} / \mathbf{C r},}$ & $\begin{array}{c}\mathbf{E}_{\mathrm{st}}, \\
\mathbf{V}\end{array}$ \\
\hline SS & 58.3 & 3.1 & 3.4 & 35.2 & _- & 1.09 & 11.35 & 10.35 & _ \\
\hline $\mathrm{SS} 50 \mathrm{~h}$ in $0.05 \mathrm{M} \mathrm{H}_{2} \mathrm{SO}_{4}$ & 66.8 & 2.7 & 3.9 & 26.6 & _- & 1.44 & 9.85 & 6.82 & -0.209 \\
\hline $\mathrm{SS}_{\mathrm{t.t.}}$ & 64.9 & 7.2 & 7.0 & 20.9 & - & 0.97 & 2.90 & 2.99 & - \\
\hline $\mathrm{SS}_{\text {t.t. }} 50 \mathrm{~h}$ in $0.05 \mathrm{M} \mathrm{H}_{2} \mathrm{SO}_{4}$ & 65.4 & 9.1 & 12.2 & 13.3 & - & 1.34 & 1.46 & 1.09 & -0.300 \\
\hline
\end{tabular}

Table 2. Amounts of the Constituent Elements in the Respective Chemical State on the Surface of Stainless Steel Evaluated by XPS

\begin{tabular}{|c|c|c|c|c|c|c|c|}
\hline Samples & $\mathbf{F e}^{\mathbf{0}}$ & $\mathbf{F e}$ & $\mathbf{C r}$ & $\mathbf{C r}$ & $\mathbf{C r}^{\mathbf{3 +}}$ & $\mathbf{A l}^{\mathbf{0}}$ & $\mathbf{A l}^{3+}$ \\
\hline \hline $\mathrm{SS}$ & 39.3 & 60.7 & 39.7 & 39.0 & 21.3 & 0 & 100 \\
\hline SS after 50 h immersion in $0.05 \mathrm{M} \mathrm{H}_{2} \mathrm{SO}_{4}$ & 50.8 & 49.2 & 21.2 & 78.8 & 0 & 0 \\
\hline
\end{tabular}



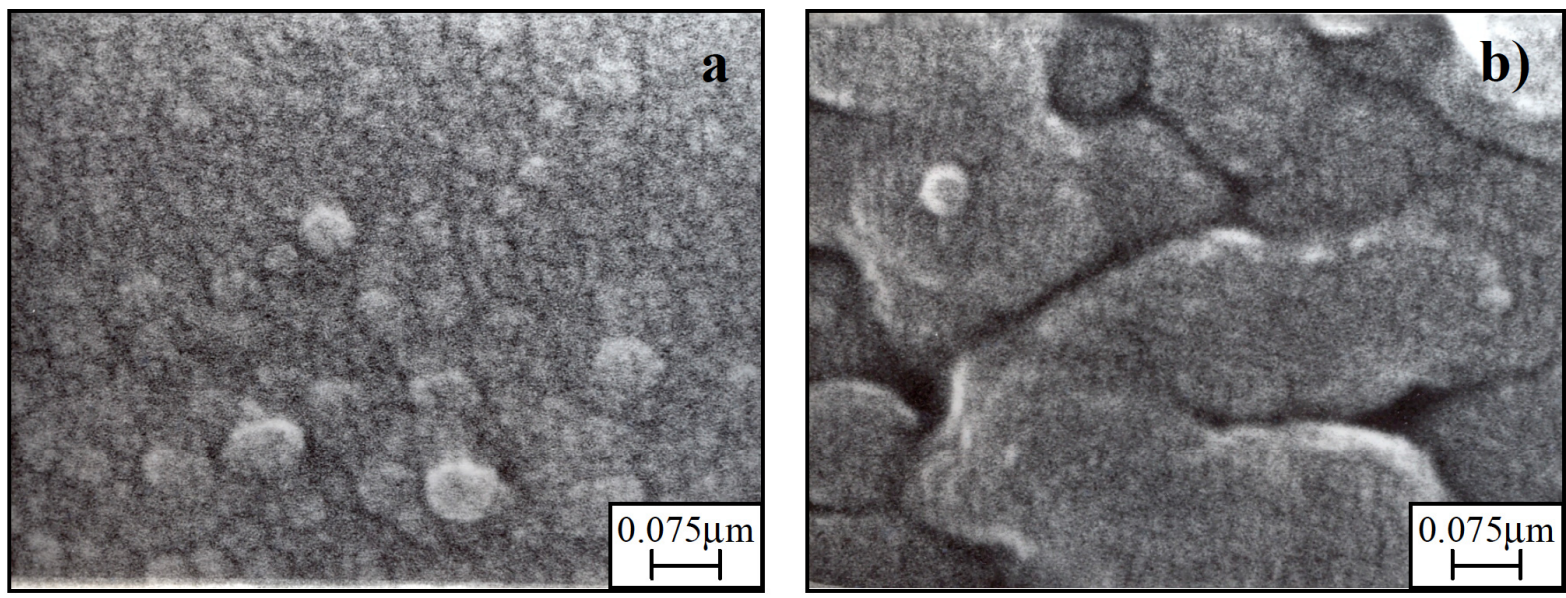

Fig. (3). SEM images of stainless steel before (a) and after thermally treatment (b).

Table 3. Amounts of the Constituent Elements in the Respective Chemical State on the Surface of Thermally Treated Stainless Steel Evaluated by XPS

\begin{tabular}{|c|c|c|c|c|c|c|}
\hline Samples & $\mathrm{Fe}^{0}$ & $\mathrm{Fe}^{3+}$ & $\mathrm{Cr}^{0}$ & $\mathrm{Cr}^{3+}$ & $\mathbf{A \mathbf { l } ^ { 0 }}$ & $\mathbf{A l}^{3+}$ \\
\hline $\mathrm{SS}_{\text {t.t. }}$ & 0 & 100 & 0 & 100 & 0 & 100 \\
\hline
\end{tabular}

$0.05 \mathrm{M} \mathrm{H}_{2} \mathrm{SO}_{4}$ solution, to which various concentrations of $\mathrm{Ce}^{4+}$ have been added.

For the non-treated thermally steel (Fig. 6a) the change in $\mathrm{E}_{\mathrm{st}}$ at concentrations ranging up to about $0.3 \mathrm{ppm} \mathrm{Ce}$ ions is relatively small. Upon increasing further the concentration a considerable shift of $E_{s t}$ in positive direction is being registered. At concentrations about $115 \mathrm{ppm} \mathrm{E}_{\mathrm{st}}$ reaches values $\sim+0.510 \mathrm{~V}$. Upon further increase in the concentration of $\mathrm{Ce}^{4+}$ in $0.05 \mathrm{M} \mathrm{H}_{2} \mathrm{SO}_{4} \mathrm{E}_{\mathrm{st}}$ is changing only slightly and at concentration $1000 \mathrm{ppm}$ the shift in positive direction reaches a value of $0.570 \mathrm{~V}$. $\mathrm{E}_{\text {st }}$ practically does not change further at the next concentration values.

The strong shift in $\mathrm{E}_{\mathrm{st}}$ in positive direction (from -0.942 $\mathrm{V}$ up to $-0.286 \mathrm{~V}$ ) in the case of thermally treated steel (Fig. 6b) is realized at relatively low concentrations of $\mathrm{Ce}^{4+}$ $(0.3 \mathrm{ppm})$. Upon increasing the concentration of $\mathrm{Ce}^{4+}$ in 0.05 $\mathrm{M} \mathrm{H}_{2} \mathrm{SO}_{4}$ further (from 0.3 to $0.9 \mathrm{ppm}$ ) $\mathrm{E}_{\mathrm{st}}$ varies to a

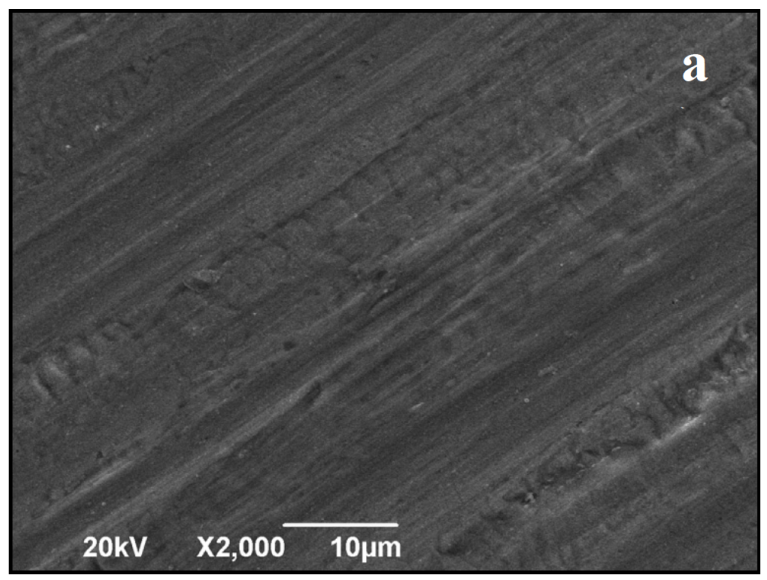

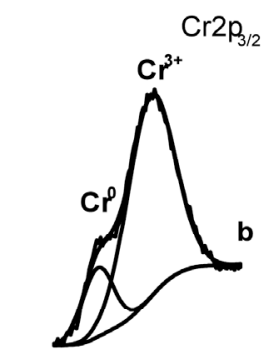
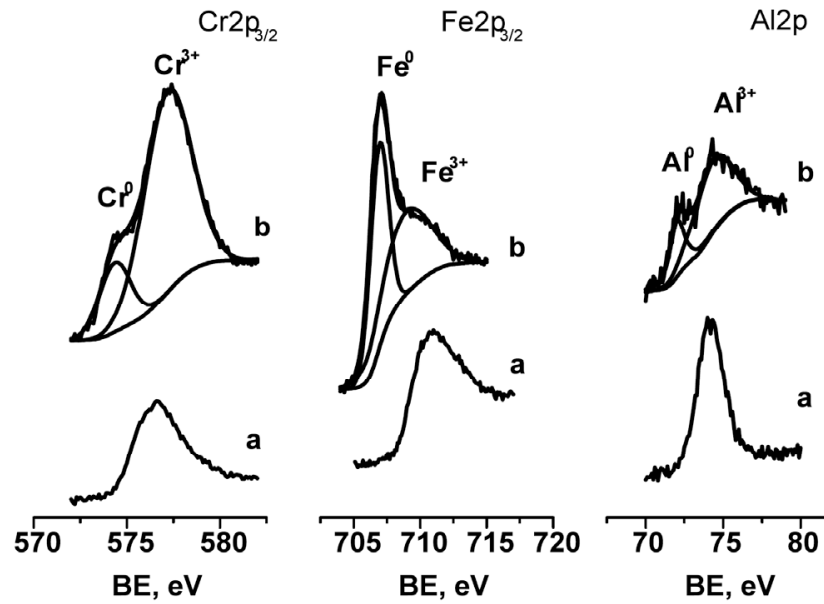

Fig. (4). $\mathrm{Cr} 2 \mathrm{p}_{3 / 2}, \mathrm{Fe} 2 \mathrm{p}_{3 / 2}$ and A12p X-ray photoelectron spectra of $\mathrm{SS}_{\text {t.t. }}$ (a) and $\mathrm{SS}_{\text {t.t. }}$ after $50 \mathrm{~h}$ immersion in $0.05 \mathrm{M} \mathrm{H}_{2} \mathrm{SO}_{4}(\mathbf{b})$.

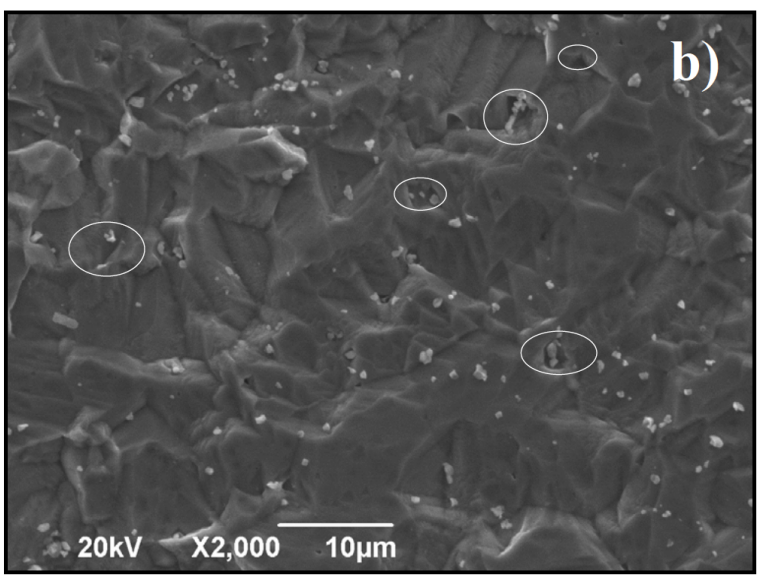

Fig. (5). SEM images of thermally treated stainless steel before (a) and after immersion $50 \mathrm{~h}$ in $0.05 \mathrm{M} \mathrm{H}_{2} \mathrm{SO}_{4}$ (b). 
(a)

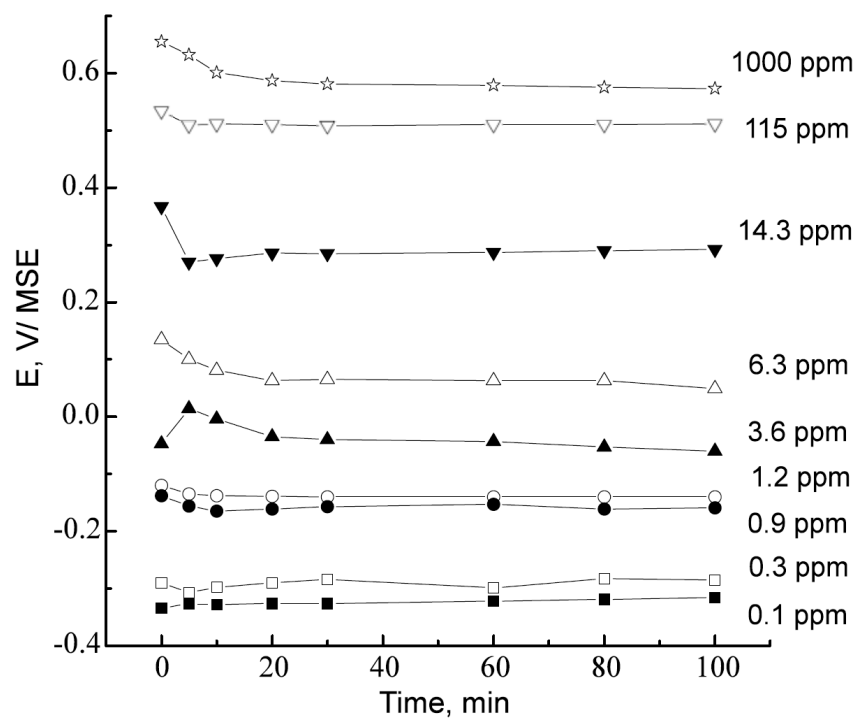

(b)

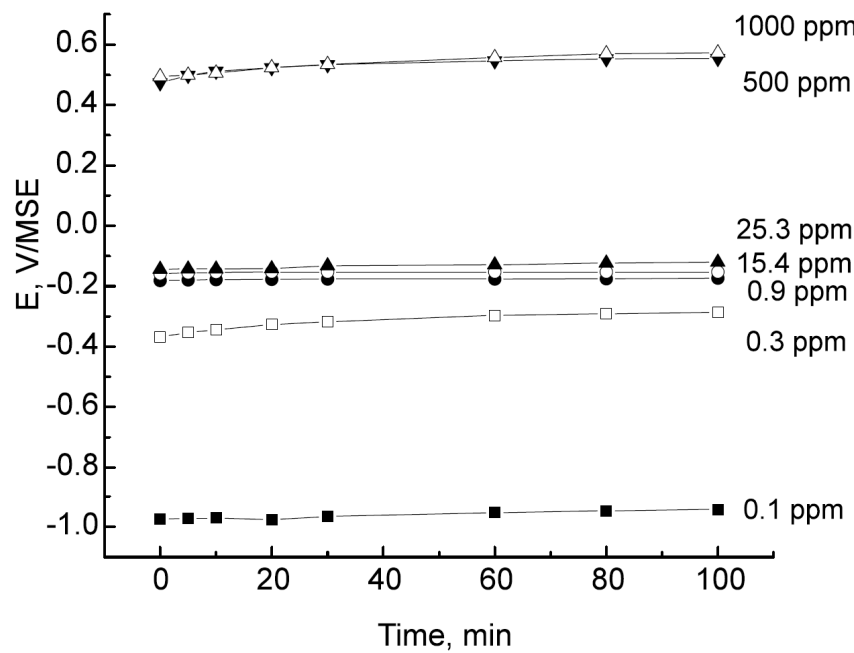

Fig. (6). Evolution of the open-circuit potential for $\mathrm{SS}$ and $\mathrm{SS}_{\text {t.t. }}$ at different concentrations of $\mathrm{Ce}^{4+}$ in $0.05 \mathrm{M} \mathrm{H}_{2} \mathrm{SO}_{4}$.

considerably smaller degree, while in the interval 0.9$25.3 \mathrm{ppm}$ this shift in positive direction is quire small.

The obtained results show that upon increasing the $\mathrm{Ce}^{4+}$ concentration in the corrosion medium the $\mathrm{E}_{\mathrm{st}}$ for $\mathrm{SS}$ is shifting in a certain proportional dependence varying from $\sim$ $0.316 \mathrm{~V}$ up to $\sim+0.570 \mathrm{~V}$. For $\mathrm{SS}_{\text {t.t. }}$ this shifting has a jumplike course - it jumps from $-0.942 \mathrm{~V}$ (at $\mathrm{Ce}^{4+}$ ions concentration $0.1 \mathrm{ppm}$ ) to $-0.175 \mathrm{~V}$ (at $\mathrm{Ce}^{4+}$ ions concentration $0.9 \mathrm{ppm})$. In the next step of $20-30$ times increase in the concentration of $\mathrm{Ce}^{4+}$ ions (15.4-25.3 ppm) preservation of $\mathrm{E}_{\mathrm{st}}$, is registered whereupon it reaches values $\sim-0.150--0.120 \mathrm{~V}$. Further follows 20-50 times increase in the concentration of $\mathrm{Ce}^{4+}$ ions $(500-1000 \mathrm{ppm})$ and $\mathrm{E}_{\mathrm{st}}$ is shifting strongly in positive direction and it acquires now values of $\sim+0.510-+0.570 \mathrm{~V}$, which are characteristic of $E_{\mathrm{st}}$ for the non-treated thermally SS at the same inhibitor concentration. (a)

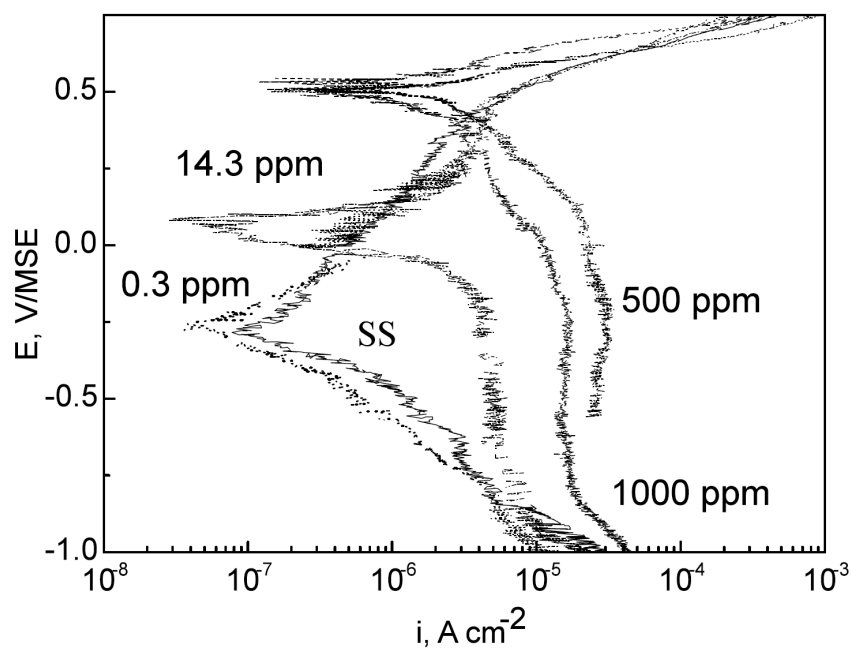

(b)

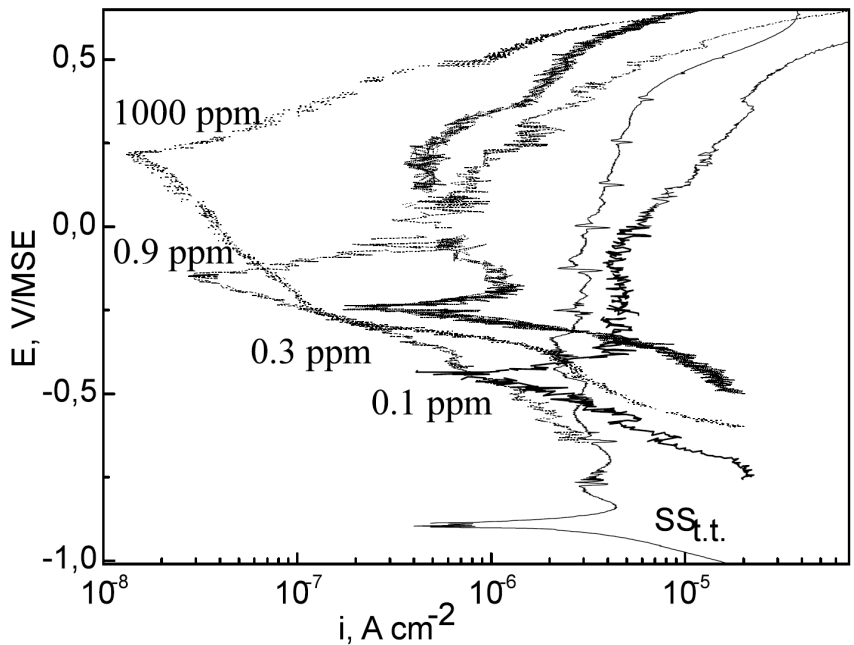

Fig. (7). Potentiodynamic E-lgi curves of SS (a) and $\mathrm{SS}_{\text {t.t. }}$ (b) at different concentrations of $\mathrm{Ce}^{4+}$ in $0.05 \mathrm{M} \mathrm{H}_{2} \mathrm{SO}_{4}$.

\subsection{Potentiodynamic Measurements of $\mathrm{SS}$ and $\mathrm{SS}_{\mathrm{t} \text {.t. in }}$ 0.05 $\mathrm{M} \mathrm{H}_{2} \mathrm{SO}_{4}$, Containing $\mathrm{Ce}^{4+}$ Ions}

The potentiodynamic curves, obtained for SS in the presence of $\mathrm{Ce}^{4+}$ ions in the corrosion medium (Fig. 7a) show that the ions shift substantially its corrosion potential $\left(\mathrm{E}_{\text {corr }}\right)$ in the positive direction - from $\sim-0.285 \mathrm{~V}$ to $\sim$ $+0.510 \mathrm{~V}$ - upon increasing the inhibitor concentration from 0.3 to $1000 \mathrm{ppm}$. It is important to point out that the values for $E_{\text {corr }}$, obtained by means of extrapolation of the anodic and cathodic potentiodynamic curves in the presence of $\mathrm{Ce}^{4+}$, were juxtaposed with the values of $E_{\text {st }}$ (Fig. 6a), determined on the basis of the E- $\tau$ dependences (regime of open circuit ) finding good coincidence. At the same time the changes in the corrosion current density $\left(\mathrm{i}_{\text {corr }}\right)$ in the presence of $\mathrm{Ce}^{4+}$ are insignificant - they remain close in value to the passive state current of the steel in the absence of $\mathrm{Ce}^{4+}$. Obviously in the case of non-treated thermally steel the inhibiting action of $\mathrm{Ce}^{4+}$ ions is expressed only in a strong shift in the corrosion potential in positive direction (Table 4). One can observe, 
however, that at $\mathrm{Ce}^{4+}$ concentrations $500-1000 \mathrm{ppm}$ the measured values for $i_{\text {corr }}$ are higher - this is an effect, on which we shall comment further below.

In the case of thermally treated steel $\left(\mathrm{SS}_{\mathrm{t} \text { t. }}\right)$ (Fig. $\left.7 \mathbf{b}\right)$ the increase in the inhibitor concentration in the corrosion medium leads to a substantial decrease in the corrosion current intensity - from $\sim 1.5 \times 10^{-6}$ (in the absence of $\mathrm{Ce}^{4+}$ ) to $\sim 3.2 \times 10^{-8} \mathrm{~A}^{-\mathrm{cm}^{-2}}$ (at concentration of $\mathrm{Ce}^{4+} \sim 0.9 \mathrm{ppm}$ ). Upon further increase in the concentration of $\mathrm{Ce}^{4+}$ ions in the corrosion medium from $\sim 0.9 \mathrm{ppm}$ (which can be accepted to be "critical value") up to $1000 \mathrm{ppm}$, however, the change in the corrosion rate is insignificant. Also in this case, with the increase in the concentration of cerium ions, the corrosion potential is shifting strongly in positive direction (from $0.900 \mathrm{~V}$ to $\sim+0.212 \mathrm{~V}$ ), whereupon its values at all concentrations of $\mathrm{Ce}^{4+}$ are more positive than the potential of complete passivation and more negative than the potential of depassivation of the steel for the entire interval of studied $\mathrm{Ce}^{4+}$ concentrations. The lower values of $\mathrm{E}_{\text {corr }}$ determined from the respective cathodic and anodic curves at concentrations 500-1000 ppm, in comparison to $\mathrm{E}_{\mathrm{st}}$ obtained at open circuit, can be associated with reaching a stable passive state of $\mathrm{SS}_{\mathrm{t.t} .}$ at concentrations $\sim 1-15 \mathrm{ppm}$. The reasons for such a supposition become obvious from the results, represented in Fig. (6b). It can be seen that within the interval of concentrations $0.9-25.3 \mathrm{ppm}$ the established values of $E_{\mathrm{st}}$ practically coincide with $\mathrm{E}_{\mathrm{st}}$ measured for the samples of non-treated thermally steel at concentrations 1 ppm (Fig. 6a).

At the same time we should note also the fact that at $\mathrm{Ce}^{4+}$ concentrations up to $0.9 \mathrm{ppm}$ in the corrosion medium (Fig. 7b) the anodic potentiodynamic curves for the $\mathrm{SS}_{\mathrm{t.t.}}$ samples are analogous to those in absence of inhibitor (a passivity zone is observed). Upon increasing the concentration of the inhibitor up to $1000 \mathrm{ppm}$ the anodic branch of the curve is changing. The reason for this change is the fact that the equilibrium oxidation - reduction potential of the $\mathrm{Ce}^{4+} / \mathrm{Ce}^{3+}$ couple is reached, which enables the oxidation reaction of $\mathrm{Ce}^{3+}$ to $\mathrm{Ce}^{4+}$. The justification of this statement is based on the analogous course of the cathodic and anodic curves, obtained with Pt electrode during our investigation, which is especially focused on the oxidation -reduction reaction of the $\mathrm{Ce}^{4+} / \mathrm{Ce}^{3+}$ ion pair in sulfuric acid medium at $1000 \mathrm{ppm}$ $\mathrm{Ce}^{4+}$ concentration - for example Figs. (7b,11).

The obtained results give us the reason to draw the conclusion that in the case of thermally treated steel the presence of cerium ions (acting as an oxidative inhibitor) determines both the strong shift of $\mathrm{E}_{\mathrm{corr}}$ in positive direction, as well as the change in the character of corrosion - from corrosion in active state into corrosion under conditions of anode passivity. Obviously the cerium ions shift the total potential of the corrosion system in positive direction to potentials, characteristic for the passive state for the anodic process. In our opinion this effect is most probably owing to promoting the effectivity of the cathodic depolarization process involving not only $\mathrm{H}^{+}\left(\mathrm{H}_{3} \mathrm{O}^{+}\right)$reduction but also $\mathrm{Ce}^{4+}$ reduction.

\subsection{Estimation of the Inhibiting Effect of $\mathrm{Ce}^{4+}$ Ions}

Table 4 lists the electrochemical kinetic parameters: corrosion current density $\left(\mathrm{i}_{\text {corr }}\right)$, corrosion potential $\left(\mathrm{E}_{\text {corr }}\right)$ and degree of inhibition efficiency $(Z, \%)$, characterizing the corrosion process in the presence and in the absence of cerium ions, determined on the basis of the results represented in Fig. (7). The degree of inhibition efficiency has been calculated on the basis of the equation:

$\mathrm{Z} \%=\left(\mathrm{i}_{\text {corr }}^{\mathrm{o}}-\mathrm{i}_{\text {corr. }}\right) / \mathrm{i}_{\text {corr }}^{\mathrm{o}} \times 100$

where $i_{\text {corr }}{ }^{\circ}$ and $i_{\text {corr }}$ are the values of the corrosion current density in the absence and in the presence of cerium ions.

It is seen from the table that upon increasing the concentration of $\mathrm{Ce}^{4+}$ ions in the corrosion medium in the case of samples of thermally treated steel the degree of inhibition efficiency reaches values of $\sim 38 \%(0.1 \mathrm{ppm}$ $\left.\mathrm{Ce}^{4+}\right)$ up to $\sim 98 \%\left(0.9 \mathrm{ppm} \mathrm{Ce}^{4+}\right)$, whereupon the further increase in the concentration of $\mathrm{Ce}^{4+}$ practically does not change the degree of inhibition efficiency. At the same time the $\mathrm{Ce}^{4+}$ ions determine an insignificant decrease in the corrosion currents, respectively the relatively lower values of the degree of protection with non-treated thermally steel. In this case the inhibiting effect of the $\mathrm{Ce}^{4+}$ ions is registered at comparatively low concentrations (up to $\sim 14.3 \mathrm{ppm}$ ), whereupon a consecutive increase in their concentration in the corrosion medium leads even to a certain increase in the corrosion current of SS, respectively to the so called "negative inhibiting effect".

In order to elucidate the weaker inhibiting effect of $\mathrm{Ce}^{4+}$ in the case of corrosion of non-treated thermally steel, we determined the charge on its surface, comparing its stationary corrosion potential $\left(\mathrm{E}_{\mathrm{st}}=-0.285 \mathrm{~V}\right)$ with the potential at zero point on $\mathrm{Fe}\left(\mathrm{E}_{\mathrm{zp}}=-1.040 \mathrm{~V}\right.$ versus MSE), as it should be done in such cases [27]. Based on the expression:

$\mathrm{E}=\mathrm{E}_{\text {corr }}-\mathrm{E}_{\mathrm{zp}}$

One obtains the value for the related corrosion potential, characterizing the charge of the steel surface, equal to $+0.755 \mathrm{~V}$. Obviously in the case under consideration the steel is charged positively in regard to the corrosion medium and the adsorption of cations or positively charged complexes will be hampered. This "negative" effect will grow stronger with the increase in the positive charge of steel upon increasing the concentration of $\mathrm{Ce}^{4+}$ ions in the corrosion medium (Fig. 6a). This is one of the possible explanations for the lower inhibiting efficiency of $\mathrm{Ce}^{4+}$ in the corrosion of non-treated thermally $\mathrm{SS}$ in $0.05 \mathrm{M} \mathrm{H}_{2} \mathrm{SO}_{4}$. Moreover, it should be taken into account that the studied SS has a well-expressed ability to self-passivation, i.e. to acquire a thick passive film on the surface, which has decisive influence on its corrosion behavior [28].

As it was noted above, upon disrupting the integrity of the passive film as a result of the thermal treatment, there appear «bare» sections of the steel surface, which leads to strongly negative value of $E_{s t}$ and change in the value of the charge on the steel surface from $+0.755 \mathrm{~V}$ to $+0.140 \mathrm{~V}$, in accordance with equation (2). This decrease in the positive electric charge of the steel will facilitate to a certain extent the adsorption of $\mathrm{Ce}^{4+}$, thus explaining the higher efficiency of the cation-active inhibitor for $\mathrm{SS}_{\mathrm{t} . \mathrm{t} .}$. The obtained results give us the reason to suppose that in case of disruption of the passive film on the steel surface this will lead to a change in 
the character of adsorption of cerium ions on the thermally treated steel.

In this connection it is logical to assume that in the case of SS samples (continuous passive film) between the inhibitor and the oxidized surface there exist mainly Van-der Waals forces of interaction (physical adsorption), while in the case of $\mathrm{SS}_{\mathrm{t.t}}$ (disrupted passive film) in addition to the electrostatic forces there can appear also chemisorption interaction. The latter forces will characterize the interaction between the non-covered with passive film sections on the steel surface (the active bare iron zones, where the charge is $-1.040 \mathrm{~V}$ ) and the cerium ions. At the same time, within the range of potentials, where oxidation processes are taking place $\left(\mathrm{Me}-\mathrm{ne}^{-} \rightarrow \mathrm{Me}^{\mathrm{n}+}\right)$, the respective conjugated reaction $\mathrm{Ce}^{4+}+\mathrm{e}^{-} \rightarrow \mathrm{Ce}^{3+}$ will be occurring too, which will lead to formation of $\mathrm{Ce}^{3+}$ hydroxide compounds of the type $\mathrm{Ce}(\mathrm{OH})^{2+}$ and $\mathrm{Ce}(\mathrm{OH})_{2}{ }^{+}$[29]. The latter can form protective layer on the steel surface. They can block the bare iron sections, which also will exert influence in the direction of shifting of $\mathrm{E}_{\mathrm{st}}$ of $\mathrm{SS}_{\mathrm{t} . \mathrm{t} .}$ in positive direction and decrease in $\mathrm{i}_{\text {corr }}$.

Confirmation of such concepts about the physical nature of the $\mathrm{Ce}^{4+}$ adsorption on $\mathrm{SS}$ is given by the characteristic course of the dependence of $\mathrm{E}_{\mathrm{st}}$ on the temperature of the corrosion medium (Fig. 8). On the other hand the insignificant change in the curve $\mathrm{E}_{\mathrm{st}}-\mathrm{T}$ for $\mathrm{SS}_{\mathrm{t} \text {.t. }}$ within the entire studied temperature interval is evidence for efficient adsorption process on $\mathrm{SS}_{\mathrm{t} . \mathrm{t}}$. The obtained data about the increase in the efficiency of the inhibiting action with the increase in the concentration of $\mathrm{Ce}^{4+}$ in the corrosion medium for the thermally treated steel (Table 4) supposes an interconnection between the inhibitor concentration and the degree of surface coverage, Q, following the equation (3) [27]:

$\mathrm{Q}=\left(\mathrm{i}_{\text {corr }}^{\mathrm{o}}-\mathrm{i}_{\text {corr }}\right) / \mathrm{i}_{\text {corr }}^{\mathrm{o}}$.

where $i_{\text {corr. }}{ }$ and $i_{\text {corr }}$ are respectively the corrosion current density obtained by extrapolation of anodic and cathodic potentiodynamic curves in the absence and in the presence of various concentrations of the inhibitor in the corrosion medium.

On the basis of the obtained data about the fraction of surface coverage of steel electrode as a function of the concentration of the inhibitor, one can accept that the adsorption process obeys Langmuir's isotherm. According to this isotherm the interconnection between the fraction of surface coverage and the concentration of the inhibitor is the following:

$\mathrm{Q}=\mathrm{KC}(1+\mathrm{KC})$

respectively

$\mathrm{C} / \mathrm{Q}=1 / \mathrm{K}+\mathrm{C}$

where $\mathrm{K}$ is the adsorption constant and $\mathrm{C}$ is the concentration of the inhibitor. The dependence $\mathrm{C} / \mathrm{Q}$ as a function of $\mathrm{C}$ for the thermally treated steel is represented in Fig. (9). It is seen that the experimental data describe a linear dependence, whereupon the coefficient of the linear regression and the slope of the straight line of this dependence approach a value of 1, which proves the validity of Langmuir's isotherm in our case.

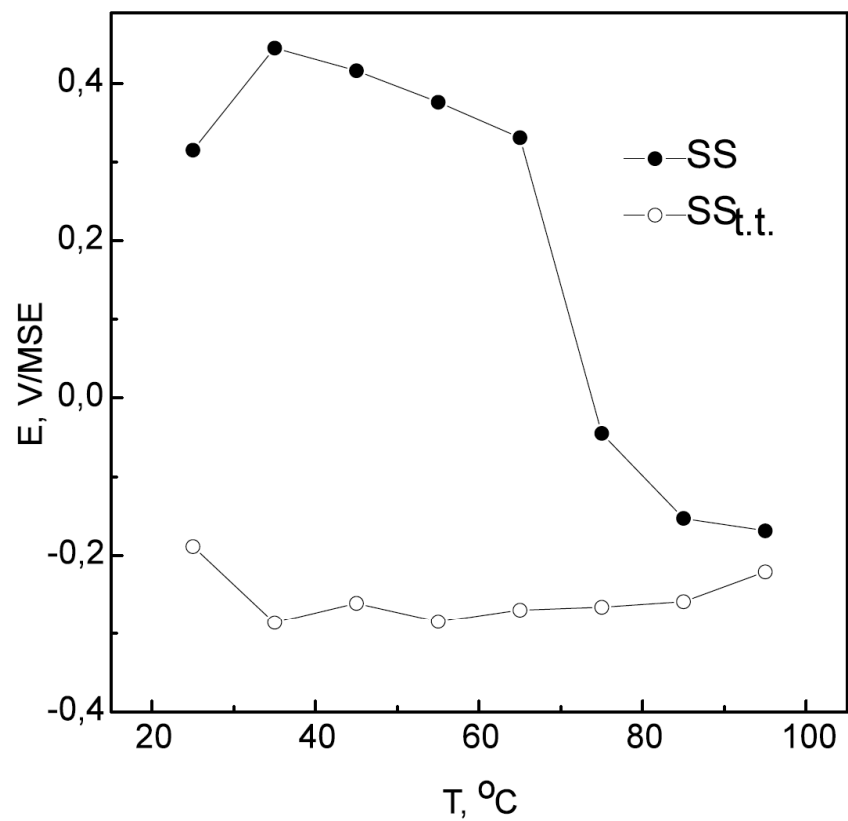

Fig. (8). $\mathrm{E}_{\mathrm{st}}$ versus temperature for $\mathrm{SS}$ and $\mathrm{SS}_{\mathrm{t} \text { t. }}$ in $0.05 \mathrm{M} \mathrm{H}_{2} \mathrm{SO}_{4}$ in the presence of $\mathrm{Ce}^{4+}$ ions.

Table 4. Electrochemical Parameters Characterizing the Corrosion Behavior of SS at Different Concentrations of the $\mathrm{Ce}^{4+}$

\begin{tabular}{|c|c|c|c|}
\hline Samples & $E_{\text {corr }}, \mathbf{V}$ & $\mathbf{i}_{\text {corr }}, \mathbf{A} \mathbf{c m}^{-2}$ & $\mathrm{Z}, \%$ \\
\hline \multicolumn{4}{|c|}{ SS without Thermal Treatment } \\
\hline SS & -0.285 & $7.5 \times 10^{-8}$ & - \\
\hline with $0.3 \mathrm{ppm}$ & -0.235 & $3.6 \times 10^{-8}$ & 51.7 \\
\hline with 14.3 ppm & -0.023 & $3.4 \times 10^{-8}$ & 54.5 \\
\hline with $500 \mathrm{ppm}$ & 0.503 & $7.1 \times 10^{-7}$ & - \\
\hline with $1000 \mathrm{ppm}$ & 0.510 & $4.1 \times 10^{-7}$ & - \\
\hline \multicolumn{4}{|c|}{ SS After Thermal Treatment } \\
\hline $\mathrm{SS}_{\mathrm{t.t.}}$ & -0.900 & $1.5 \times 10^{-6}$ & - \\
\hline with $0.1 \mathrm{ppm}$ & -0.435 & $5.8 \times 10^{-7}$ & 37.8 \\
\hline with $0.3 \mathrm{ppm}$ & -0.238 & $2.2 \times 10^{-7}$ & 86.8 \\
\hline with $0.9 \mathrm{ppm}$ & -0.156 & $3.2 \times 10^{-8}$ & 98.2 \\
\hline with $1000 \mathrm{ppm}$ & 0.212 & $1.6 \times 10^{-8}$ & 99.4 \\
\hline
\end{tabular}

The constant $K$ in equation (6) is connected with the standard free energy of adsorption $\left(\Delta \mathrm{G}^{\mathrm{o}}\right.$ ads $)$ in accordance with the equation:

$\mathrm{K}=(1 / 55.5) \exp \left(-\Delta \mathrm{G}^{\mathrm{o}}{ }_{\text {ads }} / \mathrm{RT}\right)$

The value of $K$, determined graphically based on the plot of the dependence $\mathrm{C} / \mathrm{Q}$ as a function of $\mathrm{C}$, is $44,6 \times 10^{6} \mathrm{M}^{-1}$, while the value of $\left(-\Delta \mathrm{G}_{\text {ads }}^{\mathrm{o}}\right)$ amounts to $10.35 \mathrm{KJ} \cdot \mathrm{mol}^{-1}$. The relatively low value of $\Delta \mathrm{G}^{\mathrm{o}}$ ads, however, is an indication of electrostatic forces of interaction, existing between the ions of the inhibitor and the $\mathrm{SS}_{\mathrm{t} . \mathrm{t}}$ surface. In spite of this fact the efficiency of the studied inhibitor remains high and practically it does not change with the increase in 


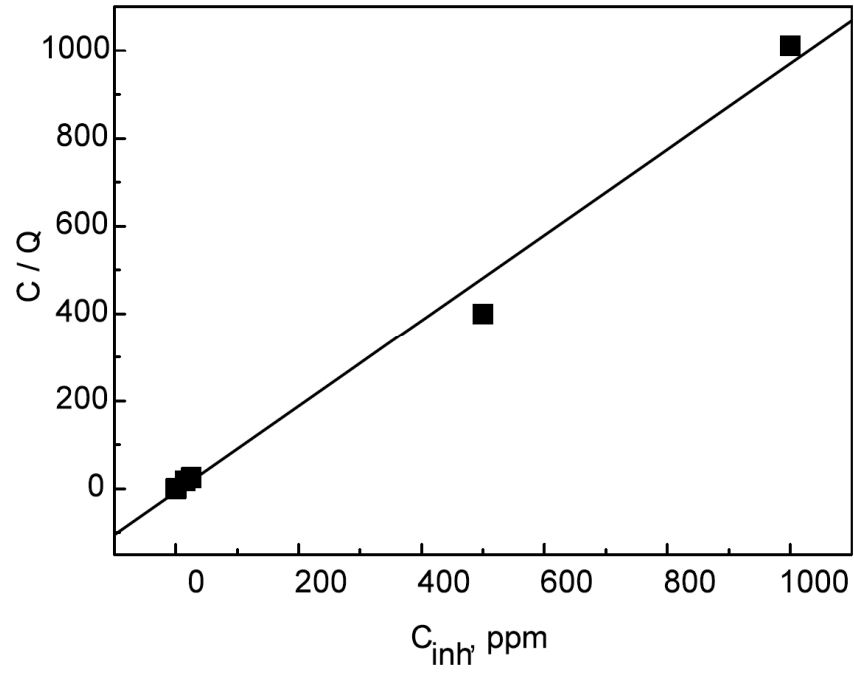

Fig. (9). Langmuir adsorption plots for $\mathrm{SS}_{\text {t.t. }}$ in $0.05 \mathrm{M} \mathrm{H}_{2} \mathrm{SO}_{4}$ at different concentration of $\mathrm{Ce}^{4+}$ ions.

temperature (Fig. 8). In our opinion, the specific action of the inhibitor on $\mathrm{SS}_{\text {t.t. }}$ is manifested in the formation of the adsorption layer, which is being transformed through phase transition (forming $\mathrm{Ce}_{2} \mathrm{O}_{3}$, bulk phase, for example), on the active anode $(\mathrm{Fe})$ sections on the surface of the $\mathrm{SS}_{\mathrm{t} . \mathrm{t}}$. Such a supposition is in accordance with the option, found recently by Scott A. Hayes et al. [29] to precipitate cerium oxides/hydroxides at much lower $\mathrm{pH}$ values that those given in the original Pourbaix.

The results from the XPS studies of the surface composition of $\mathrm{SS}_{\mathrm{t} . \mathrm{t}}$ come as a confirmation of this hypothesis. Considering the XPS analyses, after 500 hours of exposure of the thermally treated steel to the aggressive medium in the presence of $\mathrm{Ce}^{4+}$ ions $(25.3 \mathrm{ppm})$, on the surface of the studied steel in the region of Ce3d photoelectron line a certain amount of cerium is registered (1.5 at.\%) in the form of $\mathrm{Ce}_{2} \mathrm{O}_{3}$. The cerium ions are most probably intercalated inside the surface film as a result of exposure of the steel to the inhibited corrosion medium, which leads to its modifying, as a consequence of formation of mixed oxides of the type of cerium aluminates and chromates $[30,31]$. In support of such a hypothesis comes the fact that no visible corrosion damages are present on the surface of $\mathrm{SS}_{\mathrm{t.t} .}$ exposed for $500 \mathrm{~h}$ to $0.05 \mathrm{M} \mathrm{H}_{2} \mathrm{SO}_{4}$ solution in the presence of $\mathrm{Ce}^{4+}$ ions (SEM micrographs in Fig. 10). This modification of the passive film leads to a decrease in the total free energy of the system, respectively to promotion of the stability of the passive film.

Of course from purely electrochemical point of view, the ability of the inhibitor to define strongly positive oxidationreduction potential of the steel is connected with the occurrence of reduction of $\mathrm{Ce}^{4+}$ to $\mathrm{Ce}^{3+}$. In order to establish how the reduction of $\mathrm{Ce}^{4+}$ ions to $\mathrm{Ce}^{3+}$ is occurring (cathode depolarization reaction of the oxidative component of the corrosion sulfuric acid medium) within the region of potentials, characteristic of the passive state of the studied steel, we plotted the anode and cathode potentiodynamic curves, characterizing the behavior of the oxidationreduction couple $\mathrm{Ce}^{4+} / \mathrm{Ce}^{3+}$ at various concentrations of $\mathrm{Ce}^{4+}$ on indifferent support of platinum (Fig. 11). Such an approach [28], in our opinion, enables the evaluation of the mechanism of inhibitory action of the cerium ions. It allows direct juxtaposition of the change in the values of the corrosion potential (respectively corrosion current density) of the steel in the presence of cerium ions with the values of the reverse redox potentials (respectively exchange currents) of the couple $\mathrm{Ce}^{4+} / \mathrm{Ce}^{3+}$ at comparable concentrations.

From the juxtaposition of the obtained results it is seen that with the increase of the concentrations of cerium ions the equilibrium oxidation-reduction potential of the system $\mathrm{Ce}^{4+} / \mathrm{Ce}^{3+}$ is shifted in positive direction (Fig. 11 and Table 5), in accordance with the equation of Nernst, whereupon practically for all studied concentrations it is placed in the zone of potentials, characteristic of the passive state of steel (Fig. 7b). Thereupon the corrosion potentials of the steel are more negative than the equilibrium oxidation-reduction potentials of the system $\mathrm{Ce}^{4+} / \mathrm{Ce}^{3+}$. At the same time the comparison of the corrosion currents for steel in the presence of cerium ions with the exchange currents for the system $\mathrm{Ce}^{4+} / \mathrm{Ce}^{3+}$ on $\mathrm{Pt}$, at commensurable concentrations of the cerium ions, shows that they are very close to the exchange currents for the system $\mathrm{Ce}^{4+} / \mathrm{Ce}^{3+}$. At concentrations of the

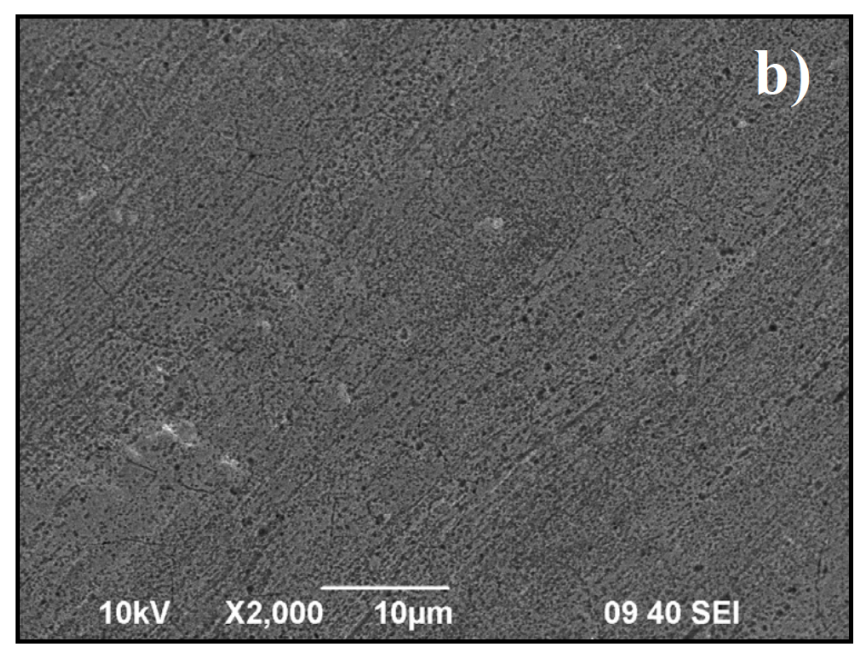

Fig. (10). SEM images on thermally treated stainless steel after $500 \mathrm{~h}$ immersion in $0.05 \mathrm{M} \mathrm{H}_{2} \mathrm{SO}_{4}$ without $\mathrm{Ce}^{4+}$ (a) and in the same media with 25.3 ppm Ce $\mathrm{pe}^{4+}(\mathbf{b})$. 
inhibitor higher than "the critical value" for $\mathrm{SS}_{\mathrm{t.t}}$, however, the corrosion currents of steel are decreased with about half an order of magnitude $\left(\sim 1 \times 10^{-8} \mathrm{~A}^{-\mathrm{CM}^{-2}}\right)$, in comparison with the exchange currents of the oxidation-reduction couple $\mathrm{Ce}^{4+} / \mathrm{Ce}^{3+}$. Evidently, the high exchange currents of the oxidation-reduction of the oxidative inhibitor will have favorable influence in case of disruption of the passive state of the steel, as a result of external action, leading to its "selfhealing".

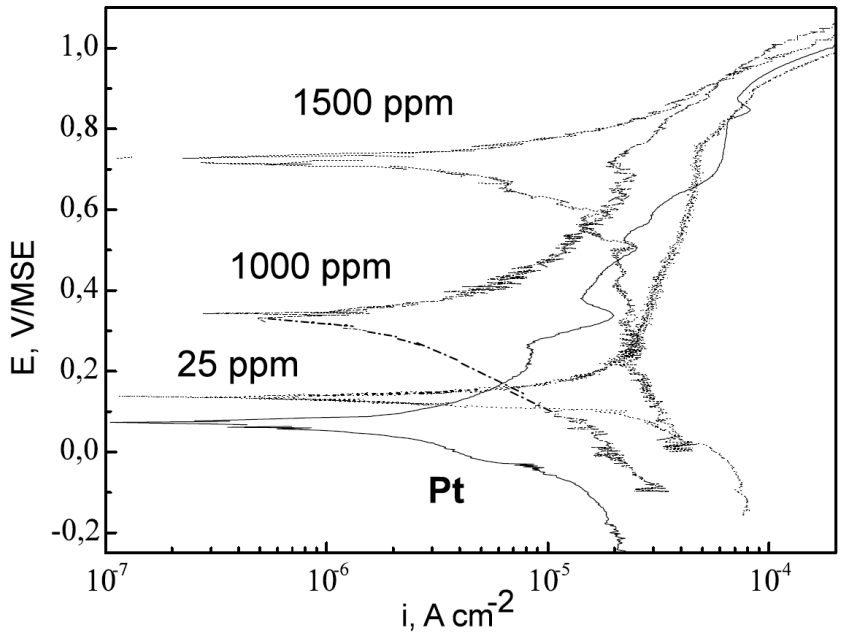

Fig. (11). Potentiodynamic E-lgi curves of Pt at three different concentrations of $\mathrm{Ce}^{4+}$ and reference curve (in the absence of inhibitor) in $0.05 \mathrm{M} \mathrm{H}_{2} \mathrm{SO}_{4}$.

Table 5. Reversible Redox Potentials $\mathbf{E}_{0}$, and Equilibrium Currents $\mathrm{i}_{0}$, of the System $\mathrm{Ce}^{4+} / \mathrm{Ce}^{3+}$ on Pt at Different Concentrations of the $\mathrm{Ce}^{4+}$ in the Corrosion Medium

\begin{tabular}{|c|l|l|}
\hline Samples & $\mathbf{E}_{\boldsymbol{o}}, \mathbf{V}$ & $\mathbf{i}_{\mathbf{0}}, \mathbf{A} \mathbf{~ c m}^{-2}$ \\
\hline \hline Pt metal & 0.070 & $2.17 \times 10^{-7}$ \\
\hline Pt with $0.3 \mathrm{ppm}$ & 0.107 & $8.99 \times 10^{-6}$ \\
\hline Pt with $25 \mathrm{ppm}$ & 0.135 & $6.35 \times 10^{-7}$ \\
\hline Pt with $1000 \mathrm{ppm}$ & 0.331 & $6.08 \times 10^{-7}$ \\
\hline Pt with $1500 \mathrm{ppm}$ & 0.722 & $7.67 \times 10^{-7}$ \\
\hline
\end{tabular}

The obtained results give the reason to classify the studied oxidation-reduction couple as cathode inhibitor, which does not influence directly the kinetics of the anode process. This determines the proceeding of a cathodic depolarization reaction $\left(\mathrm{Ce}^{4+}+\mathrm{e}^{-} \rightarrow \mathrm{Ce}^{3+}\right)$, leading to shifting of the stationary corrosion potential of the system in positive direction reaching values, corresponding to the zone of passivity of the investigated steel, in accordance with the concepts about the so called "oxidative depolarization" [28].

\section{CONCLUSIONS}

The obtained results show that the corrosion of the nontreated thermally steel of the type OC404 in sulfuric acid medium occurs at potentials assisting the preservation of the anode passivity, i.e. under conditions of anodic control. The established shifting of the corrosion potential of steel in positive direction upon addition of cerium ions to sulfuric acid aggressive medium characterizes these ions as cathode type of inhibitor. Thereupon the concentrations have been determined, at which the cerium ions in their role of cathode inhibitor with oxidative action, facilitate efficiently the processes of self-passivation, as a consequence of the decrease in the total free energy of the system and this leads to stabilization of the passive state of the steel.

In the cases when the steel has been treated thermally, as a result of the disruption of the native passive steel and the revealing of sections rich in iron on the surface, the stationary corrosion potential of the steel is shifted with about $0.7 \mathrm{~V}$ in negative direction, whereupon the corrosion process is limited by the cathode reaction of hydrogen evolution. Also in this case the addition of cerium ions to the aggressive medium shifts drastically the corrosion potential of the steel in positive direction, whereupon its values, respectively the corrosion currents, are dominated by the redox potentials and by the exchange currents for the couple $\mathrm{Ce}^{4+} / \mathrm{Ce}^{3+}$. The obtained results indicate that in the presence of $\mathrm{Ce}^{4+}$ ions, which display their property as cathode inhibitor in sulfuric acid medium, the reaction of cathodic evolution of hydrogen in the course of $\mathrm{SS}_{\text {t.t. }}$ corrosion is no longer a determining factor. It is replaced by the effective cathode reaction of reduction of $\mathrm{Ce}^{4+}$ to $\mathrm{Ce}^{3+}$, occurring at much more positive potentials of $\mathrm{E}_{\mathrm{st}}$ for $\mathrm{SS}_{\mathrm{t} . \mathrm{t}}$. In the course of this transition a possibility is created to form on the surface of the thermally treated steel an effective protective film of specific phase composition.

The research work carried out on elucidating the influence of cerium ions on the corrosion behavior of SS and $\mathrm{SS}_{\mathrm{t} \text {.t. }}$ supplies information about their specific interaction with the steel surface. The XPS data show that the cerium ions determine a substantial modification of the composition (the concentration and the chemical state of the elements) of the passive film. Thereupon the ratio iron to chromium is changed and especially to aluminum, respectively the ratio between their oxides, in favor of the latter elements, which restores (in the case of $\mathrm{SS}_{\mathrm{t} \text { t.t. }}$ ) and improves (in the case of $\mathrm{SS})$ the passive state, respectively the corrosion stability of the studied steel.

\section{ACKNOWLEDGEMENTS}

This paper has been completed with the support of the National Fund for Scientific Investigations under Contract DO 02-242/ TK 01-185. The authors are grateful for the access to the scientific equipment for part of the electrochemical measurements donated to Prof. A. Milchev (Institute of Physical Chemistry, Bulgarian Academy of Sciences) by the Alexander von Humboldt Foundation, Germany.

\section{CONFLICTS OF INTEREST}

\section{Declare to none.}

\section{REFERENCES}

[1] Nonnenmann M. New high-performance gas flow equalizing metal supports for exhaust gas catalysts. Automobilitech Z 1989; 91: 18592.

[2] Lox ES, Engler BH, Frennet A, Bestin JM. Catalysis and automotive pollution control III: environmental catalysis-mobile sources. Elsevier: Amsterdam 1995; pp. 1559-63.

[3] Kritzer P. Corrosion in high-temperature and supercritical water and aqueous solutions. J Supercrit Fluid 2004; 29: 1- 29. 
[4] Kapar J, Fornasiero P, Graziani M. Use of CeO2-based oxides in the three-way catalysis. Catal Today 1999; 50: 285-98.

[5] Nikolova D, Stoyanova E, Stoychev D, Stefanov P, Marinova T. Anodic behavior of stainless steel covered with an electrochemically deposited Ce2O3-CeO2 film. Surf Coat Technol 2006; 201: 1559-67.

[6] Stoyanova E, Nikolova D, Stoychev D, Stefanov P, Marinova T. Effect of $\mathrm{Al}$ and $\mathrm{Ce}$ oxide layers electrodeposited on OC 4004 stainless steel on its corrosion characteristics in acid media. Corros Sci 2006; 48: 4037-52.

[7] Guergova D, Stoyanova E, Stoychev D, Atanasova G, Avramova I, Stefanov P. Influence of calcination of SSOC 4004 with alumina or ceria layers on their passive state in different acid media. Bulgarian Chem Commun 2008; 40: 227-32.

[8] Nickolova D, Stoyanova E, Stoychev D, Avramova I, Stefanov P. Protective effect of alumina and ceria oxide layers electrodeposited on stainless steel in sulfuric acid media. Surf Coat Technol 2008; 202: 1876-88.

[9] Stoyanova E, Guergova D, Stoychev D, Avramova I, Stefanov P. Passivity of OC 404 steel modified electrochemically with $\mathrm{CeO} 2-$ $\mathrm{Ce} 2 \mathrm{O} 3$ oxide layers in sulfuric acid media. Electrochim Acta 2010; 55: 1725-32.

[10] Achmetov NS. General and Inorganic Chemistry (in Russian) Publ Moscow: House Vyshaya Shkola 1988.

[11] Virtanen S, Ives MB, Sproule GI, Schmuki P, Graham MJ. A surface analytical and electrochemical study on the role of cerium in the chemical surface treatments of stainless steels. Corros Sci 1997; 39: 1897-913.

[12] Bethencourt M, Botana FJ, Calvino JJ, Marcos M, RodríguezChacón MA. Lanthanide compounds as environmentally-friendly corrosion inhibitors of aluminium alloys: a review. Corros Sci 1998; 40: 1803-19.

[13] Montemor MF, Simoes AM, Ferreira MG. Composition and corrosion behaviour of galvanised steel treated with rare-earth salts: the effect of the cation. Prog Org Coat 2002; 44:111-20.

[14] Arenas MA, de Damborenea JJ. Growth mechanisms of cerium layers on galvanised steel. Electrochimica Acta 2003; 48: 3693-8.

[15] Arenas MA, de Damborenea JJ. Surface characterization of cerium layers on galvanized steel. Surf Coat Technol 2004; 187: 320-5.

[16] Arenas MA, de Damborenea JJ. Interference by cerium cations during the multi-step zinc dissolution process in a chloride containing electrolyte. Corros Sci 2006; 48: 3196-207.

[17] Pardo A, Merino MC, Arrabal R, et al. A surface characterization of cerium layers on galvanized steel. Corros Sci 2006; 48: 3035-48.
[18] Montemor MF, Pinto R, Ferreira MG. Chemical composition and corrosion protection of silane films modified with $\mathrm{CeO} 2$. Electrochim Acta 2009; 54: 5179-85.

[19] Oliver M, Lanzutti A, Motte C, Fedrizzi L. Influence of oxidizing ability of the medium on the growth of lanthanide layers on galvanized steel. Corros Sci 2010; 52: 1428-39.

[20] Sathiyanarayanan S, Jeyaprabha C, Muralidharan S, Venkatachari G. Inhibition of iron corrosion in $0.5 \mathrm{M}$ sulfuric acid by metal cations. Appl Surf Sci 2006; 252: 8107-12.

[21] Li Xianghong, Deng Shuduan, Mu Guannan, Qu Q. The synergistic inhibition effect of rare earth cerium (IV) ions and iso-vanillin on the corrosion of cold rolled steel in $1 \mathrm{M} \mathrm{H} 2 \mathrm{SO} 4$ solution. Mater Lett 2007; 61: 1514-7.

[22] Li Xianghong, Deng Shuduan, Fu Hui, Mu Guannan. Synergistic inhibition effect of rare earth cerium (IV) ion and anionic surfactant on the corrosion of cold rolled steel in $\mathrm{H} 2 \mathrm{SO} 4$ solution. Corros Sci 2008; 50: 2635-42.

[23] Li Xianghong, Deng Shuduan, Fu Hui, Mu Guannan, Zhao Ning. Synergism between rare earth cerium (IV) ion and vanillin on the corrosion of steel in $\mathrm{H} 2 \mathrm{SO} 4$ solution: weight loss, electrochemical, UV-VIS, FTIR, XPS and AFM approaches. Appl Surf Sci 2008; 254: 5574-86.

[24] Li Xianghong, Deng Shuduan, Fu Hui, Mu Guannan. Synergistic inhibition effect of rare earth cerium (IV) ion and 3, 4dihidroxybenzaldehye on the corrosion of cold rolled steel in H2SO4 solution. Corros Sci 2009; 51: 2639-51.

[25] Saji V. A review on recent patents on corrosion inhibitors. Recent Pat Corros Sci 2010; 2: 6-12.

[26] Tomashov N.D, Chernova G.P. Theory of corrosion and corrosionstable Materials. (in Russion) Publ. Moscow: House Metallurgia 1993.

[27] Rosenfeld IL. Corrosion inhibitors (in Russian) Publ. Moscow: House Khimia 1977.

[28] Tomashov ND, Chernova GP. Passivity and protection of metals from corrosion (in Russian) Publ. Moscow: House Nauka 1965.

[29] Hayes Scott A, Yu Pu, O'Keefe Thomas J, O'Keefe Matthew J, Stoffer James O. The phase stability of cerium species in aqueous systems. I. E-pH diagram for the Ce-HClO4-H2O system. J Electrochem Soc 2002; 149: C623-30.

[30] Damyanova SI, Perez CA, Shmal M, Bueno JM. Characterization of ceria-coated alumina carrier. Appl Catal A 2002; $234: 271-82$.

[31] Avramova I, Stefanov P, Nikolova D, Stoychev D, Marinova TS. Characterization of ceria-coated alumina carrier. Composite Sci Technol 2005; 65: 1663-167.

(C) Guergova et al.; Licensee Bentham Open .

This is an open access article licensed under the terms of the Creative Commons Attribution Non-Commercial License (http:/creativecommons.org/licenses/by-nc/ 3.0/) which permits unrestricted, non-commercial use, distribution and reproduction in any medium, provided the work is properly cited. 